\title{
AGARWOOD: THE PRECIOUS TREE
}

\author{
Gitanjali Devi ${ }^{1} \bowtie$ \\ ${ }^{1}$ Department of Nematology, Assam Agricultural University, Jorhat-13, Assam, India
}

\section{ABSTRACT}

Agarwood (Aquilaria spp.) is an expensive fragrant wood. It is used for its aromatic and phototherapeutic properties. Terpenoids (sesquiterpenes) and flavonoids are the chemical constitutes of agarwood .The aromatic properties and resin character of agarwood is influenced by the species, geographical distribution of the plant. This review emphasizes the mass cultivation of Aquilaria tree by various induction technologies.

Received 6 July 2021

Accepted 18 July 2021

Published 31 July 2021

Corresponding Author

Gitanjali Devi, gitanjali_devi@yah oo.in

DOI 10.29121/

granthaalayah.v9.i7.2021.4103

Funding: This research received no specific grant from any funding agency in the public, commercial, or not-for-profit sectors.

Copyright: (C) 2021 The Author(s). This is an open access article distributed under the terms of the Creative Commons Attribution License, which permits unrestricted use, distribution, and reproduction in any medium, provided the original author and source are credited.

OPEN
Keywords: Agarwood, Aquilaria Spp, Aromatic and Medicinal Value, Induction Technology

\section{INTRODUCTION}

The forest tree, Aquilaria (Thymelaeaceae: angiosperms) also known as agarwood, aloeswood or ghruwood is a native to Southeast Asia. Agarwood is composed of a resin in the stem, branches and roots of the Aquilaria tree. Agarwood and its essential aromatic oil have achieved great enriching and sacred importance from time immemorial Hansen (2000), Persoon and Beek (2008). In India, as early as 1400 BCE, it is described as a fragrant product in Vedas. Materia Medica written by Dioscorides, described several medicinal properties of agarwood. Agarwood's medicinal use was mentioned in the Ayurvedic Susruta Samhita. The agarwood shows several therapeutic values like as antiasthma, antidiabetes, antioxidation, anti-inflammatory, digestive, analgesic, anticancer, anti-arthritic, and antipyretic Wang et al. (2018). The root extract is used as a stimulant and tonic.

During thirteenth century, for international trade India was the main source of agarwood. In ancient Assam (Kamarupa), the agarwood known as Xasipat (writing material) and aloe-oil was mentioned in Xuanzang's travel history and the book 'Harshacharita'. Most of the species of Aquilaria, at maturity reaches 40 meters height and 80 centimeters wide. Agarwood formation is a physiological change that causes on Aquilaria tree to cope with the external factor. An insect, ambrosia beetle (Dinoplatypus chevrolati) feeds on trunk and roots of trees. Later on, a mold (Phialophora 
parasitica) infection occurs, and the tree produces a beneficial self-protection substance (oily resin) to obscure infections Gibson (1977). The resin increases the mass and density of the wood, colour changes from a light beige to yellow, orange, red, dark brown or black. As the infection proceeds, the tree produces a dark aromatic resin, the marketable product which is also known as aloes, agar, gaharu or jinko. The aromatic product is used in global market for different perfumery industries. In natural forests, around $10 \%$ of natural mature tree can produce agarwood. Only nine species of the genus Aquilaria, out of twenty-one species are known to produce agarwood. Aquilaria malaccensis (synonyms: A.agallocha, A.secundaria), A.crassna and A.sinensis are the main producer species of agarwood Ng et al. (1997). However, resin character of agarwood is depending upon the species, their geographical distribution, position of infection in branch, trunk or root, time taken for infection by the fungus, and methods of harvesting and processing.

\section{PHYTOCHEMICAL PROPERTIES}

The agarwood oil is composed of more than 300 chemical compounds Naef (2011), Chen et al. (2012), Wang et al. (2018). The chemical contituents are extracted by a series of steam distillation process. The amount and type of agarwood phytochemical compounds of each study vary depending on the agarwood species, extraction methods and analysis used. The chemical compounds include sesquiterpenes like cadinanes, eudesmanes, valencanes, eremophilanes, guaianes, prezizanes, vetispiranes, aromadendrene, agarospirol, $\beta$-agarofuran, guaiol and aristolene Dash et al. (2008), Jong et al. (2014) and chromones,2-(2-phenylethyl) chromones (PECs) Naef (2011), Jayachandran et al. (2014). For agarwood grading, an effective chemical marker- aromadendrene and valencene, the amount was found to be greater in higher grade agarwood Pasaribu et al. (2015). Similarly, the amount of 2(2-phenylethyl) chromone and 2-(2-4-methoxy-phenylethyl) chromone were found as high as $66.47 \%$ in the high-grade agarwood Ishihara et al. (1993). The PEC derivatives, are also important photochemical for aromatic agarwood.

\section{CULTIVATION PRACTICES}

\section{Soil and climatic conditions for agarwood farming:}

The tree grows well at different forests ecosystem, generally 750 meters above sea level with the temperature range from $20^{\circ} \mathrm{C}$ to $33^{\circ} \mathrm{C}$ and relative humidity ranging from $77-85 \%$.

Propagation is done by seed by selecting potential species. The propagation to sapling could be done immediately after bursting. Large size seeds are developed from older mother tree and the germination rate is 80 to $90 \%$ within one week in the month of June-July. It can be grown in the farmland, home garden or inter-cropping with other trees. In private nurseries a large number of Aquilaria seedlings can be 
produced in a well-drained soil Blanchette et al. (2015). After 3-4 years of plantation the plant will die due to stagnant water. After attaining a height of $60-90 \mathrm{~cm}$, the seedlings are transplanted into the main field. For rapid growth and development, the trees require spacing of $2 \times 2 \mathrm{~m}$. In tea plantation area the agar tree can be introduced as shade tree.

\section{Artificial inoculation in agarwood farming:}

In order to produce a sustainable high valued agarwood in a short period of time in young trees, plantation can be done by using techniques of artificial inoculation. In China, the practice of artificial induction for agarwood formation by injuring the trees was observed during 300 CE. Many approaches like nail setting, holing, burning, use of chemical, insect and pathogen inducing technique are widespread in agarwood plantation. A common method in agarwood farming is to inoculate trees with the fungus in the xylem of Aquilaria. Within a short period of time (2-3 hrs), infection occurs to all the parts of the tree leading to wounds on the tree. It produces a damage sap. After four months, resinous wood forms around the wound in the root portion, branch as well trunk of the tree. Many pure culture strains of fungi isolated from natural agarwood were found to be effective biological agents to induce agarwood formation Cui et al. (2013), Siburian et al. (2015), Sangareswari et al. (2016). However, due to utilization of different fungal consortium, the fungal inoculation gives rise to restricted and lower quality of agarwood. The process is laborious and time consuming to achieve maximum colonized surface area on the tree for production of better quality of agarwood.

\section{Induction technology}

In order to guarantee the constancy of agarwood yield from the domesticated Aquilaria trees within a short period of time, development of effective induction technology is necessary. Properly formulated inducer is able to produce artificial agarwood with same as those obtained from natural source. Some induction techniques have been developed to introduce signaling molecules directly and specifically into Aquilaria trees to initiate agarwood resin biosynthesis pathways. Chemical inducers are more suitable for mass production than physical wounding and biological inoculum Cheng et al. (2019). Chemical inducers are comprised of phytohormones, salts, minerals, and biologically derived substances Zhang et al. (2012). Appropriate release method has been developed along with the chemical formulations to ease the large-scale induction process, such as container equipped with transfusion needle, thereby time-consuming holing process can be minimized. Through chemical induction technique via transpiration process, less induction sites are needed to deliver the inducers throughout the plant. Several induction techniques are: cultivated agarwood technique (CA-kit), the whole tree agarwood inducing technique (Agar-wit) and biologically agarwood inducing technique (Agarbit) Zhang et al. (2012), Liu et al. (2013), Azren et al. (2018). CA-kit is a collective 
method based on physical wounding and chemical induction, where the inducing agent is applied into the Aquilaria tree through an aeration device inserted into the wound. Agar-wit is a transpiration assisted chemical treatment to form an overall wound in the tree where the preloaded inducer in a transfusion set is distributed through plant transpiration. This method produces more decayed tissues. In agar-bit method, inducing reagent is distributed by plant transpiration, except that the reagents are injected directly into the stems of the tree. For more targeted and directional improvement of the induction formulation, agarwood formation at the molecular level should be advocated Xu et al. (2013).

\section{Harvesting}

Harvesting is done through assortment of trees, the process of felling, and a demarcation of different collector types (local and nonlocal). An approximately 20 $\mathrm{ml}$ of oil can be extracted from $70 \mathrm{~kg}$ of wood. The average yield from a mature single tree is approximately $4 \mathrm{~L}$ that cost Rs.1, 00,000. The plant suffers from the leaf pests, Heortia vitessoides.

\section{Conservation of agarwood producing species:}

The Aquilaria tree is now listed as endangered species due to the indiscriminate harvesting from natural habitats as well as habitat loss of some of the populations of agarwood producing species. Beek and Phillips (1999) emphasized that the international trade of agarwood should be monitored which led to the addition of the main taxa on CITES Appendix-II. It is protected under Convention on International Trade in Endangered Species, 2004 (CITES) of wild fauna and flora regulation. International trade in agarwood is subjected to design to ensure that harvest and exports are not to the loss of the survival of the species in the wild Cites (2004).

The Draft Policy for sustainable Utilization of Agar wood, 2014, from the Department of Environment, Forest and Climate Change, Government of India stipulates assigned management strategies for the sustainable utilization of agarwood: Geographical distribution and resource base documentation of agarwood Espinoza et al. (2014) and Cultivation practices, market grade, value addition of products, domestic policies i.e., formation of rules and regulation for growers by the concerned state government.

\section{CONCLUSION}

Development of new products and drugs from agarwood is a promising aspect of trade. Therefore, a number of countries are interested for Aquilaria plantations. The success of these plantations depends on the prompt agarwood production in the trees. Mass cultivation of Aquilaria tree which will resolve the shortage of agarwood supply in the global market. Bioactivity screening and pharmacological exploration needs to be implemented with the constituent phytochemicals of agarwood. Further 
improvement of the induction technology and screening of better lines of Aquilaria species for resin production under breeding programme are some of the important issues of mass production and cultivation.

\section{REFERENCES}

Azren, P., Lee, Sy, Emang, D., \& Mohamed, R. (2018). History And Perspectives Of Induction Technology For Agarwood Production From Cultivated Aquilaria In Asia: A Review. Journal Of Forestry Research., 30, 1-11. Retrieved from 10.1007/S11676-018-0627-4

Beek, H. V., \& Phillips, D. (1999). Agarwood: Trade And Cites Implementation In Southeast Asia. Traffic Southeast Asia, Malaysia.

Blanchette, R., Jurgens, J., \& Beek, H. (2015). Growing Aquilaria And Production Of Agarwood In Hill Agro-Ecosystems. In I. L. U. M. I. T. E. H. E. E. K \& R. L. (Eds.), (pp. 66-82). Akansha Publishing House Delhi.

Chen, H., Wei, J., Yang, J., Zhang, Z., Yang, Y., Gao, Z., \& Gong, B. (2012). Chemical Constituents Of Agarwood Originating From The Endemic Genus Aquilaria Plants. Chemistry And Biodiversity, 9, 236-250.

Cheng, S., Isa, N., Ismail, I., \& Zainal, Z. (2019). Agarwood Induction: Current Developments And Future Perspectives. Frontiers Of Plant Science, 10(122). Retrieved from 10.3389/ Fpls.2019.00122

Cites. (2004). Convention On International Trade In Endangered Species Of Wild Fauna And Flora. Appendices I, Ii, And Iii. Unep-Wcmc. Ii, And Iii. Retrieved from Http://Www .Cites.Org/Eng/App/Appendices.Php

Cui, J., Guo, S., Fu, S., Xiao, P., \& Ml, W. (2013). Effects Of Inoculating Fungi On Agilawood Formation In Aquilaria Sinensis. Chinese Science Bulletin.

Dash, M., Patra, J., \& Panda, P. (2008). Phytochemical And Anti-Microbial Screening Of Extracts Of Aquilaria Agallocha Roxb. African Journal Of Biotechnology, 7, 3531-3534.

Espinoza, E., Lancaster, C., Kreitals, N., Hata, M., Cody, R., \& Blanchette, R. (2014). Distinguishing Wild From Cultivated Agarwood (Aquilaria Spp.) Using Direct Analysis In Real Time And Time Of Flight Mass Spectrometry. Rapid Communications In Mass Spectrometry, 28, 1-9.

Gibson, I. (1977). The Role Of Fungi In The Origin Of Oleoresin Deposits Of Agaru In The Wood Of Aquilaria Agallocha Roxb. Journal Of Science, 6, 16-26.

Hansen, E. (2000). The Hidden History Of Scented Wood. Saudi Aramco World, 51, 2-13.

Ishihara, M., Tsuneya, T., \& Uneyama, K. (1993). Fragrant Sesquiterpenes From Agarwood. Phytochemistry, 33, 1147-1155.

Jayachandran, K., Sekar, I., Parthiban, K., Damodarasamy, A., \& Suresh, K. (2014). Analysis Of Different Grades Of Agarwood (Aquilaria Malaccensis Lamk.) Oil Through Gc-Ms. Indian Journal Of Natural Products And Resources, 5(1), 44-47.

Jong, P., Pascale, T., \& Rozi, M. (2014). Gas Chromatography-Mass Spectrometry Analysis Of Agarwood Extracts From Mature And Juvenile Aquilaria Malaccensis. International Journal Of Agriculture And Biology, 16, 644-648.

Liu, Y., Chen, H., Yang, Y., Zhang, Z., Wei, J., Meng, H., Chen, W., Feng, J., Gan, B., Chen, X., Gao, Z., Huang, J., Chen, B., \& Chen, H. (2013). Whole Tree Agarwood Inducing Technique: An Efficient Novel Technique For Producing High Quality Agarwood In Cultivated Aquilaria Sinensis Trees.Molecules., 18, 3086-3106.

Naef, R. (2011). The Volatile And Semi-Volatile Constituents Of Agarwood, The Infected Heart- 
wood Of Aquilaria Species: A Review. Flavour And Fragrance Journal, 26, 73-87.

Ng, L., Chang, Y., \& Kadir, A. (1997). A Review On Agar (Gaharu) Producing Species. Journal of Tropical Forest Products, 2(2), 272-285.

Pasaribu, G., Waluyo, T., \& Pari, G. (2015). Analysis Of Chemical Compounds Distinguisher For Agarwood Qualities. Indonesian Journal Of Forestry Reseasrch, 2.

Persoon, G., \& Beek, H. V. (2008). Growing 'The Wood Of The Gods. Agarwood Production In Southeast Asia. In: Smallholder Tree Growing For Rural Development And Environmenatal Services, 245-262.

Sangareswari, N., Parthiban, K., Kanna, S., Karthiba, L., \& Saravanakumar, D. (2016). Fungal Microbes Associated With Agarwood Formation. American Journal Of Plant Sciences, 7 , 1445-1452.

Siburian, R., Siregar, U., Siregar, I., \& Santoso, E. (2015). Identification Of Morphological Characters Of Aquilaria Microcarpa In The Interaction With Fusarium Solani. International Journal Of Sciences: Basic And Applied Research, 20, 119-128.

Wang, S., Yu, Z., Wang, C., Wu, C., Guo, P., \& Wei, J. (2018). Chemical Constituents And Pharmacological Activity Of Agarwood And Aquilaria Plants. Molecules, 23(2).

Xu, Y., Zhang, Z., Wang, M., Wei, J., Chen, H., Gao, Z., Sui, C., Luo, H., Zhang, X., \& Yang, Y. (2013). Identification Of Genes Related To Agarwood Formation: Transcriptome Analysis of Healthy And Wounded Tissues Of Aquilaria Sinensis. Bmc Genomics, 14, 227-227.

Zhang, X., Liu, Y., Wei, J., Yang, Y., Zhang, Z., Huang, J., Chen, H., \& Liu, Y. (2012). Production Of High Quality Agarwood In Aquilaria Sinensis Trees Via Whole Tree Agarwood Induction Technology. Chinese Chemical Letters, 23, 727-730. 